\title{
Exploring the Challenge of Adoption from the Perspec- tive of Iranian Infertile Women
}

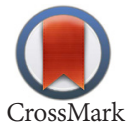

Seyede Batool Hasanpoor-Azgahdy ${ }^{1}$, Masoumeh Simbar ${ }^{2 *}$, Abouali Vedadhir ${ }^{3}$, Leila Amiri Farahani ${ }^{1}$

1. Department of Reproductive Health, Faculty of Nursing \& Midwifery, Iran University of Medical Sciences, Tehran, Iran.

2. Research Center for Safe Motherhood, Department of Reproductive Health and Midwifery, Faculty of Nursing and Midwifery, Shahid Beheshti University of Medical Sciences, Tehran, Iran.

3. Department of Anthropology, Faculty of Social Sciences, University of Tehran, Tehran, Iran.

ditation: Hasanpoor-Azgahdy, SB, Simbar, M, Vedadhir, AA \& Amiri Farahani, L 2016, 'Exploring the challenge of adoption from the perspective of Iranian infertile women', Journal of Client-Centered Nursing Care, vol. 2, no. 1, pp. 19-26. https://doi.org/10.32598/jccnc.2.1.19

: https://doi.org/10.32598/jcenc.2.1.19

Article info:

Received: 08 Apr. 2015

Accepted: 22 Nov. 2015
Keywords:

Infertility, Adoption, Qualitative study

\begin{abstract}
A B S T RA C T
Background: Adopting another person's child by infertile couple might not alleviate their pain so much but direct the suffering and pain of infertility towards parenthood and parental experience. Therefore, this study aimed to explore the challenges of adoption to assist in proper planning to improve the quality of adoption.

Methods: This qualitative study was conducted with conventional content analysis method on 25 women with primary and secondary infertility. The study was conducted in Vali-e-asr Reproductive Health Research Center, Tehran, Iran. Sampling method was done purposefully and data were gathered from semi-structured interviews. The interviews continued until saturation of the data. Concurrent with data collection, their analysis was done based on the conventional content analysis method.

Results: The main concepts derived from data were categorized into 3 main themes and their subthemes as follows: 1) Legal and cultural barriers (importance of blood ties, priority of treatment before deciding to adopt a child, and strict legal requirements), 2) The attitude of the husband towards adopted child (adoption as a good deed, husband preferred to continue the treatment as much as possible, the decision of the husband depends on the reaction of others around them, and preferring remarriage over adoption), 3) Attitude of the others (fear of disclosure of adoption in the future and negative attitudes of the society).

Conclusion: The findings of this study showed that in our society, the importance of blood ties, cultural factors, and infertility treatment are among the barriers to adoption. The results show that it is critical to raise the awareness and enlightenment in society through the media to minimize the socio-cultural consequences of adoption.
\end{abstract}

\section{* Corresponding Author:}

Masoumeh Simbar, PhD

Address: Research Center for Safe Motherhood, Department of Reproductive Health and Midwifery, Faculty of Nursing and Midwifery, Shahid Beheshti University of Medical Sciences, Tehran, Iran.

Tel: +98 (21) 8820251

E-mail: msimbar@yahoo.com 


\section{Background}

nfertility as a life crisis, accompanies with a vast range of social, psychological, physical, and financial problems (Avidime et al. 2013; Greil et al. 2010). More than 80 million people worldwide are infertile. Infertility rates are different across the countries from less than 5\% to more than 30\% (Daar \& Merali 2002). In Iran, in a comprehensive study which was conducted to determine the prevalence of infertility in 2005 , it was found that $24.9 \%$ of the couples had experienced primary infertility during their married life (Vahidi et al. 2009). Although infertility is not a disease, its impact on all aspects of a person's life can cause mental, social, and emotional disorders (Hasanpoor-Azghdy et al. 2015).

Despite the huge progress in the diagnosis and treatment of infertility and the great efforts usually done by the couples to have a baby, even in the best equipped health centers, some infertile couples do not succeed to have a child. High failure rate of these approaches cast doubts on using them. Furthermore, infertility treatments are too expensive and not all families afford them or can access them (Yassini et al. 2012; Ezenwankwo et al. 2014; Joshi et al. 2015; Ojelabi et al. 2015).

Also, some infertile couples may be reluctant to get pregnant by using complicated and invasive technologies, so they can experience parenthood through adoption (Ismaili 2004; Aliakbari \& Tavakol 2010). Adoption is among the most important strategies in dealing with the negative consequences of infertility and it can help cure the damaged mental aspects of infertile couples and improve relations between spouses. Also couples feel the joy of parenting and resolve mental health problems caused by lack of child in their lives (Abubakar et al. 2013; Joshi et al. 2015). However, adoption has been neglected and considered an obsolete method. There are different attitudes toward adoption; some of them are extremely negative (Bagheri et al. 2009).

Adoption is a legal relationship formed by adopting a child by a man and woman who are not his or her biological parents (Nguefack et al. 2014). For most infertile couples, decisions on the adoption or use of third party reproductive technology (For example, egg donation, embryo, etc.) are not made easily and fast. During the preliminary medical treatments, once couples are hopeful towards success of the treatment, adoption creates great concern. This is the fear they don't want to face during the quest for having a biological child (Razzaghi 2006). Qualitative research findings in Iran also showed that the challenge of adoption is the dilemma that made respondents face with serious tensions. Interest or disinterest in adopting a child, insistence or opposition of the husband to adopt a child, intervention of the couple's families, and so on were among serious concerns of infertile women. The child's unknown family tree and reaction of relatives and acquaintances to the newcomer baby were among the issues that made the couples hesitant in adopting a child. Most of infertile women oppose to adopt a child and mention emotional issues, social problems, people's words, and appearance of adopted child's parents as the causes of their disagreements (Abbasi-Shavazi et al 2005; Fahami et al. 2010; Bokaie et al. 2012).

The results of Avidime et al. (2013) study showed that $42.6 \%$ of all participants would like to adopt a child, if there was no solution to their infertility. In a study in Cameroon, $84.8 \%$ of the subjects were aware of the adoption and attitude of $76.7 \%$ of them was good towards adoption; however, only $1 \%$ had adopted a child at the time of the study which was due to their enthusiasm towards having a child (Nguefack et al. 2014). In a study by Yassini et al. (2012), only $4.5 \%$ of infertile couples had an adopted child at the time of study. Most infertile couples have some constraints on adoption, so the first and most important step to assist these couples is to identify their challenges with regard to adoption. Without real knowledge of the factors affecting adoption, it is not possible to support and help these couples.

The cultural reasons that impede adoption were seen in all studies done in developing countries (the studies that we had access to them) (Adewunmi et al. 2012; Bokaie et al. 2012; Nguefack et al. 2014; Joshi et al. 2015). Also, studies have shown that investigating the various aspects of infertility is incomplete and futile, without paying attention to the socio-cultural context of the society in which the infertile person lives. Because the cultural context is very important in shaping infertility life experiences (Gannon et al. 2004; Inhorn 2008; Greil et al. 2010), this qualitative study explored the challenge of adoption to help prepare proper planning to improve the quality of adoption process based on deep understanding of these challenges.

\section{Materials \& Methods}

To explain the perception of infertile women in their assessment of adoption, a qualitative approach was used with the conventional content analysis method. In this research, the study population consisted of infertile women with primary and secondary infertility. Participants with secondary infertility had no pregnancy that led to a live birth. The study setting was Vali-e-Asr Reproductive Health Research Center, Tehran, Iran, which infertile women from 
different parts of the country get acquainted with it by the medical staff, acquaintances, or infertile partners.

Sampling was purposively done with the maximum diversity and range which could further contribute to the generalization of the findings (Polit \& Beck 2006). The participants were selected with different ages, duration of marriage, duration of infertility, types of treatment, duration of treatment, educations, occupations, living in urban and rural areas, and incomes. These difference added to the reliability of the obtained data. Inclusion criteria for participants consisted of having primary or secondary infertility due to just gynecological causes, not having a living child (in women with secondary infertility), not adopting a child, not having chronic diseases or mental illnesses, and willing to participate in the study.

After approval of the Ethics Committee of Shahid Beheshti University of Medical Sciences and presenting the introduction letter to research center, The researcher explained to the participants the study purpose, reason for choosing infertile women for the study, their role in the study, advantages of their participation in the research, confidentiality of their information, their right to participate or decline the research and how to contact the researcher. Then, after the participants agreed to take part in the study, their informed written consents were taken.

To select information-rich participants who can actively take part in the study, the researcher followed this procedure. In the morning and before the interviews, the researcher reviewed files of all participants supposed to be visited on the day and chose some of them who met the inclusion criteria. Then, the researcher checked out the behavior and manner of the selected women through talking with the physician and midwives of the ward and during the examination. This procedure, along with the guidance of medical staff (with regard to their frequent contacts with infertile women), were helpful in choosing information-rich participants who can provide their experiences to the researcher.

To collect data, semi-structured individual interviews, observation, field notes, and files of patients were used. The interviews were done in a room located on the second floor of Infertility Center which was quiet and completely at the researcher's disposal. After participants' agreements, the recorder was turned on and interview began (using an interview guide form) with this question:

"Did you ever think about the issue of adoption or if there was a conversation between you and your husband about this issue?"
During the interview, the nonverbal behaviors of participants were paid attention to. For each participant, an interview was conducted for 60 to 90 minutes. Interviews continued until the data saturation which occurred with the $23^{\text {rd }}$ participant. To be on the safe side, two more women were interviewed and the number of interviews reached 25. After each interview, the information which was recorded with the permission of participants were transcribed word by word in the shortest possible time and after 2 to 3 times of listening to the records. Finally, they were typed. Along with the process of data collection, their analysis was performed, too (Polit \& Beck 2006).

Observation of reactions and conversations of infertile people with others was done in different sections of the Infertility Center such as the waiting room, the admission office, examination room, sonography room, and diagnosis procedure room, but the researchers did not notice any situation in which the women talked about adoption with each other or the medical staff to have field note in this regard.

To analyze the data, conventional content analysis method was used. Qualitative content analysis is a research method used for mental interpretation of written data content. In this method, during the process of systematic classification, codes and themes are identified out of the views of study participants. Then, the codes, which are extracted based on the units of meaning drawn from participants' descriptions, are classified with regard to their differences or similarities and their themes are identified (Spannagel et al. 2005). In this way, the interview transcripts were reviewed several times to get completely familiar with their contents, then the codes were extracted based on the units of meaning drawn from participants' descriptions and classified with regard to their differences or similarities and finally the related themes were identified.

To be ensured of the data credibility, different techniques such as diversity of participants, long-term exposure to participants and research setting, providing information about the study objectives, continuous evaluation of the data, sound recording and transcription, data analysis immediately after the interview, and using its feedback for the next interview, were used. Moreover, the obtained data were verified and revised through review by a number of study participants and independent experts. To check transferability of the study, the data were presented to some infertile women who did not participate in the research and were asked to compare the results with their own experiences (Polit \& Beck 2006) 


\section{Results}

Analysis of the data drawn from the interviews and field observations led to the formation of 3 main themes and their subthemes, which are shown in Table 1.

\section{Cultural and legal barriers}

This theme includes the following 3 subthemes: the importance of blood ties between the child and parents; priority of treatment before deciding to adopt a child, and strict legal terms.

Perception and experience of the participants indicated that blood ties between the child and parents are of great importance for some of them. These women believed that when the child is not from their blood and flesh, she or he will leave them in adulthood or his or her real parents might take him or her back. Others believed that they try hard to raise a child who is from other parents.

"It is of no worth to raise that child, I'd like to be his/her real mother, when I do not have a sense of motherhood, how can I be kind towards that child... when you gave birth to a child that was kick in 'in your stomach, It's a good and different feeling. I like the kid to be mine and of my own blood."

(30 years old woman, diploma, housewife, 7 years of infertility)

Most of these women wanted to have a biological child, believing that a mother can only express genuine and sufficient affection to her biological child, because adopted child is not form their blood.

"I do not accept that child as my own, perhaps I show kindness towards his/her but that kindness, you are a woman as well, is not by heart."

(31 years old lady, BA, translator, 2 years of infertility)
The duration and type of treatment are the other determining factors for some infertile women to think about the adoption. Some participants said that as the duration of their infertility period was short or they have not completed treatment yet, they would not think about adoption.

"No way, because our period of infertility is not so long, it is two and a half years now. For example, we say to a lady who has no child for 13 years that go and adopt a child, but she is also hopeful to IVF. We did not think like this, because my tubes were treated soon, they got opened and I'm so hopeful that may God give me a baby soon."

(27 years old woman, diploma, housewife, 2.5 years of infertility)

Some participants mentioned that as long as the doctors have hopes that they give birth to their own children, they will try any type of treatment, and after that they will think about adoption.

Some participants who have searched for information about adoption, mentioned that legal requirements for adoption in our country were very difficult, especially the financial terms that an infertile couple should afford to apply for adoption. These terms would not let them to do so.

"Even if someone wants to adopt a child, it is too difficult to do so. You must earn a good income. Now the government takes it so hard.... I surfed the Internet to see that what the requirements are to keep custody of a child, it was written that you must have enough money in your bank account. Your husband must never be addicted. You as mother should not be over 50 years old."

(35 years old woman, diploma, housewife, 7 years of infertility)

Table 1. The main obtained themes and their subthemes.

\begin{tabular}{cc}
\hline Main themes & Subthemes \\
\hline Legal and cultural barriers & $\begin{array}{c}\text { The importance of blood ties } \\
\text { Priority of treatment before deciding to adopt a child } \\
\text { Strict legal terms and conditions } \\
\text { Adoption, a good deed } \\
\text { Attitude of the husband towards the adopted child }\end{array}$ \\
$\begin{array}{c}\text { Husband prefers to continue the treatment as much as possible } \\
\text { The decision of the husband depends on the reaction of other } \\
\text { persons around }\end{array}$ \\
Attitude of others & $\begin{array}{c}\text { Preferring remarriage over adoption } \\
\text { Fear of disclosure of adoption in the future } \\
\text { Negative attitudes of the society }\end{array}$ \\
\hline
\end{tabular}


Attitude of the husband towards the adopted child

This theme includes 4 subthemes: child adoption as a good deed, preference of the husband to continue the treatment as long as possible, decision of the husband is dependent on the reactions of those people around, and preference of the husband to remarry rather than adopt a child.

Participants' experiences indicated that one of the major factors in making decision of infertile women to adopt a child is their husbands. Perception and experience of participants show different decisions made by their husbands with regard to adopting a child. Some men agree with adoption due to their beliefs that raising these children is a kind of good deed, but the majority of them disagree with it.

"My husband will probably agree. Because when it comes to this conversation, he agrees. He says if a family raise these children, it is a good deed. My husband is a philanthropist. I know he would agree."

(39 years old lady, BA, language teacher, 2 years of infertility)

"If I talk about adopting a child in front of my husband, he would leave me."

(28 years old woman, guidance school, housewife, 2 years of infertility)

For some participants, decision of some men about adoption depends on the reaction of those around.

"But I think if I talk to my husband about it, he looks the reaction of others around to accept it or not."

(25 years old woman, associate degree, nurse, 2 years of infertility)

Some participants expressed that their husbands preferred to remarry rather than adopt a child and others mentioned that their husband preferred to continue treatment as much as possible rather than adopt a child.

"My husband prefers to remarry 10 times rather than adopt a child."

(37 years old lady, diploma, secretary, 12 years of infertility)

"I talked a couple of times with my husband but he never said yes or no. My husband said: why you get hope- less so soon. He said: let's continue treatment as long as possible. Let's see what will happen.'

(30 years old woman, diploma, housewife, 2.5 years of infertility)

\section{Attitudes of others}

This theme includes two subthemes: fear of disclosure of adoption in the future and the negative attitudes of the society.

Judgment and stand of the society regarding adoption have a significant effect on the decision and belief of participants to adopt a child. Some participants mentioned the fear of disclosure of child adoption in the future as the reason for not getting along with the issue of adoption, as that will cause mental trauma to the adopted child.

"When you tell him/her or s/he hears it from someone else, it will affect him/her, it hurts."

(31 years old lady, diploma, housewife, 6 years of infertility)

Most participants mentioned that attitude of other people towards adoption is negative. Couples who take measures to adopt a child, are stigmatized by other people and it will add to their problems.

"In the little villages, if you adopt a child who is not yours, people say words which lead to more problems."

(43 years old woman, elementary school, housewife, 14 years of infertility)

\section{Discussion}

The decisions of our study participants regarding their willingness or unwillingness to adopt a child were based on different factors. These factors comprised cultural and legal barriers, attitude of husband towards adoption, attitude of others around about adoptions, and the laws governing the adoption terms in the country. All these issues indicate the unwillingness of the majority of participants to adopt a child. In this regard, Bokaie et al. (2012) reported that in $85 \%$ of cases, Iranian infertile women were unwilling to have an adopted child, while in Nigeria, 59.3\% were opposed to adoption. The high acceptance level in Nigeria is most probably due to the growth of knowledge about adoption with the improvement of public awareness through the media, social research, and other sources (Ojelabi et al. 2015). Results of Bokaei et al. study showed that in $78 \%$ of cases, hope to give birth to their own child is 
the main obstacle in adoption. Most couples prefer to have no child or think of new treatments.

Preference of any type of treatment over adoption, the parents' being left alone by the adopted child when they get old, fear of disclosure of adoption, and negative attitude of society towards adoption are themes found in our study which were similar to themes found in other studies in India (Bharadwaj 2003; Joshi et al. 2015), Nigeria (Ojelabi et al. 2015), and Pakistan (Sami \& Tazeeni 2012). Bagheri et al. in their study concluded that if couples felt comfortable in terms of attitude of society and others towards adoption, they would have a more favorable attitude and acceptance towards adoption (Bagheri et al. 2009). For example, in Western countries, adoption is a well-known practice and many organizations are ready to help with infertile couples' wants. It seems that adoption in America is higher than all other countries of the world. In 2000, the number of adopted children in this country was 127985 cases $(61.5 \%)$ (Bernal et al. 2007). Surprisingly, in Gambia, infertility is considered as a disgrace, but child rearing is a strong and rooted tradition. About $43 \%$ of infertile couples in Gambia have an adopted child (Sundby 1997). Although one of the concepts extracted from our study data was to adopt a child as "doing a good deed," which was also reported by Aliakbari \& Tavakol (2010) in their qualitative study, performance of infertile couples in Iran is very low (despite this belief) with regard to adoption.

In Nigeria, the most common reasons for reluctance to adopt a child were cultural reasons such as unknown family history of the child, lack of legal rights (like inheritance), fear of child's abnormal behavior or disease (such as mental illness or epilepsy that were inherited from his or her biological parents), and finally fear of the being left alone by the adopted child (Adewunmi et al. 2012; Ojelabi et al. 2015). It seems that in our study, the focus was not on the themes related to children, because participants had no intention of adoption.

In line with the beliefs of our study participants, for some respondents in Nigeria, the prospective of adoption was psychologically unacceptable. They felt that they could not love this child like their own birth child (Adewunmi et al. 2012; Ojelabi et al. 2015). Some participants claimed that if they want to adopt a child, they adopt a child of their own relatives. In this case, they are both aware of family history of the child and even if the child is supposed to inherit future wealth from them, he or she is a relative and acquaintances. In this regard, Adewunmi et al. (2012) showed that respondents were willing to adopt a child of a relative, friend, or distant acquaintance.
Nigerian infertile women with positive tendency towards adoption, mentioned family reasons such as lack of support from their husbands, parents, or husband's family for their disagreements in marital relations and disinterest in adoption (Ojelabi et al. 2015). This issue was similar the theme of "the decision of the husband depends on the reaction of peoples around" in our study.

The duration and type of the treatment were other determining factors for our study participants to think about the adoption. A study in the United States of America also showed that infertility period for more than 5 years (Bernal et al. 2007) and in Cameroon for over 10 years (Nguefack et al. 2014) were significantly associated with a positive attitude towards adoption.

Participants complained of strict laws and regulation that the government has enforced for adoption, especially the financial terms that an infertile couple should have to adopt a child. According to the Welfare Organization, the complexity of the legal process to adopt a child in Iran is one of the obstacles in adoption Bokaie et al. 2012). In Nigeria, infertile couples who earn more than $650 \$$ a year can afford more than other couples to deal with strict rules of adoption in terms of financial terms. While this might be discouraging for couples who earn less and live in poorer conditions (Adewunmi et al. 2012). In Iran, the maximum age for child adoption is 50 years (Iran, No. 4015) and in Nigeria for a woman who has no children, this age is 45 years and since it take a long time for infertile couples to make a decision on adopting a child, this law creates a problem for them (AGBO, 2014).

Although the issue of "mahramiat" (the concept of unmarriageable kin) of children to parents are important for our participants, religious reasons that Adewunmi et al. (2012) mentioned in their study, were not considered by our participants. In the study of Adewunmi et al. a number of Christian respondents were not willing to adopt a child, since they felt that adoption means lack of faith in God, because their prayers were not answered for the child.

Authorities of child adoption mentioned that among the applicants of child adoption, those infertile couples in which the husband was infertile, were more willing to adopt a child. Studies in Iran also show that the problem of $70 \%$ to $80 \%$ of infertile couples, who are applicant of child adoption, is related to male infertility. One justification for this issue is the patriarchal dominance governing over child adoption process. Couples that their infertility is related to men are more willing to adopt a child (Naghinia 2000; Sardari 2001; Razzaghi 2006). The results of these studies were in line with the themes found in our study. In 
couples whose infertility is related to the wife, remarriage of the husband might be chosen as a solution which sometimes is associated with the stress and divorce. In this case, we see families with two or more wives (Razzaghi 2006). Unfortunately, this reflects the aspects of gender hierarchical and hegemonic relationships (Healy 2000).

Comparing our obtained results with the results of studies in developed societies like Sweden shows that although infertility is a central issue of life in this country, infertile couples reduce the consequences of infertility by doing social activities and keeping children of friends and acquaintances (Wirtberg et al. 2007). In developing countries like our society, the importance of blood ties and cultural factors are barriers for child adoption and infertile couples prefer to continue treatment as much as possible and finally get divorce and choose polygamy over adoption. Also, in Cameroon one reason for infertile women opposing to the adoption is their family stigmatized (Nguefack et al. 2014). Unfortunately, despite the importance of nurturing the orphans in Islam, this religious capacity has not been used appropriately to increase the willingness for child adoption.

Our findings showed that the experiences of participants in this study about child adoption were similar to each other and like the experiences of other developing societies in which, child adoption is typically the last solution among the methods of infertility treatments that are chosen by infertile couples and in some cases, remarriage or divorce are preferred to child adoption. Therefore, we suggest that social workers, nurses, and midwives, especially those with community orientation be present in all infertility centers to provide the information about the adoption process and support infertile couples regarding the challenges that they have in the process of child adoption. This support can even be extended to the future for parents of adopted children. On the other hand, raising awareness and enlightenment in society through the media are critical to minimize the socio-cultural consequences of child adoption, because adoption is not only desirable to improve the quality of life in infertile couples, but also leads to upbringing and growth of children in a lovely environment and is beneficial for both the nation and the government.

\section{Research Limitations}

Because infertile couples with high levels of income refer to private infertility centers which the researchers were not allowed to study them, our study participants did not have a very high income. However, we tried to include among our participants, those couples who had the highest incomes.

\section{Acknowledgements}

We would like to express our heartfelt gratitude to all infertile women who participated in the study, those who generously gave their time and energy to complete the qualitative interviews. We also thank staff of Vali-e-asr Reproductive Health Research Centre and faculty of the School of Nursing and Midwifery of Shahid Beheshti University of Medical Sciences for their sincere cooperation in this study. The authors verify that this project has been financially supported by Shahid Beheshti University of Medical Sciences, Tehran, Iran.

\section{Conflict of Interests}

Authors declared no conflict of interests.

\section{References}

Abbasi-Shavazi, MJ, Asgari-Khanghah, A \& Razeghi-Nasrabad, HB 2005, '[Women and the infertility experience: a case study in Tehran (Persian)]', Women's Research, vol. 3, no. 13, pp. 91-114.

Abubakar, S, Lawan, UM \& Yasir, JN 2013, 'Knowledge and attitudes toward child adoption and fostering among infertile women in northern Nigeria', Sahel Medical Journal, vol. 16, no. 1, pp. 19-23. doi: 10.4103/1118-8561.112062

Adewunmi, AA, Etti, EA, Tayo, AO, Rabiu, KA, Akindele, RA \& Ottun, TA et al. 2012, 'Factors associated with acceptability of child adoption as a management option for infertility among women in a developing country', International Journal of Women's Health, vol. 4, pp. 365-72. doi: 10.2147/ijwh.s31598

Agbo, MC 2015, 'Socio-cultural challenges of child adoption in Eastern Nigeria in West Africa', Humanities \& Social Sciences Reviews, vol. 2, no. 1, pp. 86-93. doi: 10.5901/mjss.2013. v4n13p705

Aliakbari, F \& Tavakol, Kh 2010, '[Psychological experiences of families with adopted child (Persian)]', Behavioral Sciences Research, vol. 8, no. 2, pp. 125-32. doi: 10.1097/00004703200212000-00001

Avidime, S, Ameh, N, Adesiyun, AG, Ozed-Williams, C, Isaac, N, Aliyu, Y et al. 2013, 'Knowledge and attitude towards child adoption among women in Zaria, Northern Nigeria', Nigerian Medical Journal, vol. 54, no. 4, pp. 261-64. doi: 10.4103/03001652.119657

Bagheri, A, Latifnejad Roudsari, R, Omidi, A \& Esmaeili, H 2009, '[A comparative study of psychosocial factors affecting acknowledgment of adoption in couples with and without adopted child (Persian)]', Journal of Mashhad School of Nursing $\mathcal{E}$ Midwifery, vol. 9, no. 1, pp. 51-58.

Bernal, R, Hu, L, Moriguchi, C \& Nagypal, E 2007, Child adoption in the United States: historical trends and the determinants of adop- 
tion demand and supply 1951-2002, National Science Foundation and Northwestern University Press, New York.

Bharadwa, JA 2003, 'Why adoption is not an option in India: the visibility of infertility, the secrecy of donor insemination, and other cultural complexities', Social Science \& Medicine, vol. 56, no. 9, pp. 1867-880. doi: 10.1016/s0277-9536(02)00210-1

Bokaie, M, Farajkhoda, T, Enjezab, B, Heidari, P \& Zarchi, MK 2012, 'Barriers of child adoption in infertile couples: Iranian's views', Iranian Journal of Reproductive Medicine, vol. 10, no. 5, pp. 429-34.

Daar, AS \& Merali, Z 2002, 'Infertility and social suffering: the case of ART in developing countries', in E Vayena, PJ Rowe, PD Griffin (eds.), Current practices and controversies in assisted reproduction, World Health Organization Pub, Geneva.

Ezenwankwo, FC, Roberts, AA \& Balogun, MR 2014, 'Acceptability of child adoption in the management of infertility: A survey of women attending fertility clinics in the tertiary facilities in Lagos', Journal of Clinical Sciences, vol. 11, no. 2, pp. 35-38. doi: 10.4103/1595-9587.146497

Fahami, F, Hoseini Quchani, S, Ehsanpour, S \& Zargham, A 2010, '[Women's lived experiences of female infertility (Persian)]', Iranina Journal of Obstetrics Gynecology \& Infertility, vol. 13, no. 4, pp. 45-53.

Gannon, K, Glover, L \& Abel, P 2004, 'Masculinity, infertility, stigma and media reports', Social Science \& Medicine, vol. 59, no. 6, pp. 1169-175. doi: 10.1016/j.socscimed.2004.01.015

Greil, AL, Slauson-Blevins, K \& McQuillan, J 2010, 'The experience of infertility: a review of recent literature', Sociology of Health $\mathcal{E}$ Illness, vol. 32, no. 1. pp. 140-62. doi: 10.1111/j.14679566.2009.01213.x

Hasanpoor-Azghdy, SB, Simbar, M \& Vedadhir, A 2015, 'The social consequences of infertility among Iranian women: a qualitative study', International Journal of Fertility \& Sterility' vol. 8, no. 4, pp. 409-20.

Healy, K 2000, Social workpractice: contemporary perspectives on change, Sage Publications, Thousand Oaks.

Inhorn, MC \& Birenbaum-Carmeli, D 2008, 'Assisted reproductive technologies and culture change', Annual Review of Anthropology, vol. 37, no. 1, pp. 177-96. doi: 10.1146/annurev. anthro.37.081407.085230

'Foster parenting will be easy' 2008, Iran Newspaper, 1 September, p. 6.

Ismaili, A 2004, '[Study of family problems after adoption child (Persian)]', MA thesis, Islamic Azad University of Roodehen.

Joshi, SV, Prasad, R \& Kushwaha, AS 2015, 'A study of knowledge and attitude towards adoption amongst infertile couples', International Journal of Public Health Research, vol. 3, no 6, pp. 318-26.

Naghinia, M 2000, '[The effective factors on the conduct of infertile families in relation to adoption (Persian)]', MA thesis, Islamic Azad University of Roodehen.

Nguefack, CT, Ourtching, C, Gregory, HE \& Priso, EB 2014, 'Knowledge, attitudes and practices of infertile women on child adoption in Douala (Cameroon)', Open Journal of Obstetrics and Gynecology, vol. 4, no. 16, pp. 1065-071. doi: 10.4236/ ojog.2014.416146
Ojelabi, OA, Osamor, PE \& Owumi, BE 2015, 'Policies and practices of child adoption in Nigeria: a review paper', Mediterranean Journal of Social Sciences, vol. 6, no. 1, pp. 75-81.

Oladokun, A, Arulogun, O, Oladokun, R, Adenike Bello, F, Morhassan-Bello, IO \& Bambgoye, EA et al. 2010, 'Attitude of infertile women to child adoption in Nigeria', Nigerian Journal of Physiological Sciences, vol. 25, pp. 47-49.

Polit, DF \& Beck, CT 2006, Essentials of nursing research methods, appraisal and utilization, $6^{\text {th }}$ edn, Williams \& Wilkins, Philadelphia.

Razzaghi, R 2006, [Adoption (Persian)], $1^{\text {st }}$ edn, State Welfare Organization, Tehran.

Sami, N \& Tazeen, SA 2012, 'Perceptions and experiences of women in Karachi-Pakistan regarding secondary infertility: results from a community-based qualitative study', Obstetrics \& Gynecology International, doi: 10.1155/2012/108756

Sardari, S 2001, '[Problems and difficulties of infertile couples in relation to adoption (Persian)]', MA thesis, Iran Psychology Institute.

Spannagel, C, Glaser-Zikuda, M, Schroeder, U 2005, 'Application of qualitative content analysis in user-program interaction research', Forum: Qualitative Social Research, vol. 6, no. 2 Viewed 29 May 2005, http://www.qualitative-research.net/ index.php/fqs/article/view/469/1004

Sundby, J 1997, 'Infertility in Gambia: traditional and modern health care', Patient Education and Counseling, vol. 31, no. 1, pp. 29-37. doi: 10.1016/s0738-3991(97)01006-9

Vahidi, S, Ardalan, A \& Mohammad, K 2009, 'Prevalence of primary infertility in the Islamic Republic of Iran in 2004-2005', Asia Pacific Journal of Public Health, vol. 21, no. 3, pp. 287-93. doi: 10.1177/1010539509336009

Wirtberg, I, Möller, A, Hogström, L, Tronstad, SE \& Lalos, A 2007. 'Life 20 years after unsuccessful infertility treatment', Human Reproduction, vol. 22, no. 2, pp. 598-604. doi: $10.1177 / 1010539509336009$

Yassini, SM, Shavazi, MT \& Shavazi, NT 2012, 'Factors associated with adoption acceptance rate from the view point of infertile couples', Iranian Journal of Reproductive Medicine, vol. 10, no. 5, pp. 413-18. 